\title{
The Development of the Construction and Demolition Waste Dynamic Model
}

\author{
T. Chinda, W. Engpanyalert, A. Tananoo, J. Chaikong, and A. Methawachananont
}

\begin{abstract}
With the higher amount of buildings and infrastructures in Bangkok, Thailand, the number of construction and demolition (C\&D) waste is increasing continuously. These wastes, if not completely recycled, will create the environmental problems. This research paper concentrates on the use of a system dynamics modeling technique to develop a $C \& D$ waste recycling model. Data and related relationships were generated to develop the simulated equations to simulate the model to reflect real practices of the construction industry in Bangkok, Thailand. The simulation results reveal the improved C\&D waste recycled over time.
\end{abstract}

Index Terms-Construction and demolition waste, recycling, system dynamics modeling

\section{INTRODUCTION}

Since higher amount of building and infrastructure has been constructed in Bangkok, Thailand, the number of construction and demolition (C\&D) waste is increasing continuously [1]. The C\&D wastes, comprising of concrete, brick, metal, ceramics, roofing, gypsum, and wood, can be classified into two categories: recyclable (70\%) and non-recyclable $(30 \%)$ wastes [2]. It is, however, found that not all the recyclable wastes are yet recycled, and are dumped into landfills. The improvement of C\&D waste management, thus, helps reducing the amount of C\&D wastes and landfill requirement [3].

Reference [2] mentioned an increasing trend of C\&D waste generation of $26 \%$ from 2003-2006, following the increasing populations in Bangkok, Thailand. As C\&D waste is one of the main solid waste generators in Bangkok, its impact on the environment has become an imperative issue to the stakeholders [4]. Past research has mainly focused on the separate aspects of waste management, such as waste reduction, reuse, and recycle [5]. In this research paper, a dynamic simulation model is developed, based on system dynamics methodology, to strategically plan the C\&D waste management in Bangkok. The relationships between major factors inherently involved in C\&D waste management, such as labors, machines, and related costs are considered. It is expected that the dynamic model assists decision makers to better understand and make decisions regarding the $C \& D$ waste recycling program.

Manuscript received April 15, 2013; revised June 14, 2013.

T. Chinda is with the School of Management Technology, Sirindhorn International Institute of Technology, Thammasat University, 131 Tiwanont Rd. Bangkadi, Muang, Pathumthani 12000, Thailand (e-mail: thanwadee@siit.tu.ac.th).

\section{THE DEVELOPMENT OF CONSTRUCTION AND DEMOLITION WASTE DYNAMIC MODEL}

In this paper, the system dynamics modeling is used to develop the C\&D waste recycling model. The model consists of four sectors, namely "Cost", "Recycled Waste", "Labor and Machine", and "Leftover of C\&D Waste" sectors. Details of each sector are as following.

\section{A. The Cost Sector}

Fig. 1 shows the "Cost" sector model. The "total cost" is a function of the "cost inflow", which is the summation of the "transportation cost", the "labor cost", the "machine cost", and the "storage cost".

The "transportation cost", as in (1), is based on the amount of trucks with their fuel costs. The "labor cost" depends mainly on the amount of labors used in the sorting and recycling processes, see (2). The "machine cost", as in (3), in the same way, increases as the number of machine used in the sorting process increases. The "storage cost" refers to the cost the company pays to store the $C \& D$ waste before transferring to the next recycling steps, see (4).

Transportation cost $=$ Fuel_cost_to_recycle_shop + Truck_cost_to_recycle_shop+Fuel_and_truck_cost_for truck_to_landfill

Labor cost $=$ Exact_used_number_of_labor $* 300 * 250$

Machine cost $=((\operatorname{MEAN}(28620,39725)) * 30) *$

Machine_purchasing

Storage cost $=$ DELAY $($ Storage_capacity $*(150 * 12), 1,0)$

\section{B. The Labor and Machine Productivity Sector}

The "Labor and Machine Productivity" sector (as shown in Fig. 2) describes the labors and machines used in the sorting and recycling processes. The number of labors and machines are increasing as the recycling program proceeds, see (5), (6). These amount of labors and machines dictate the labor and machine costs the company spends. They are, however, constant when the total labor and machine productivity exceeds the amount of C\&D wastes to be recycled, or when the "cost inflow" exceeds the "environmental budget", see (7)-(9).

This environmental budget is the upper bound of budget the company could spend to implement the C\&D waste recyling program. Based on references [6], [7], 1.8 percent of total budget is used to determine the upper bound, which is 40 billion Baht in this case. 


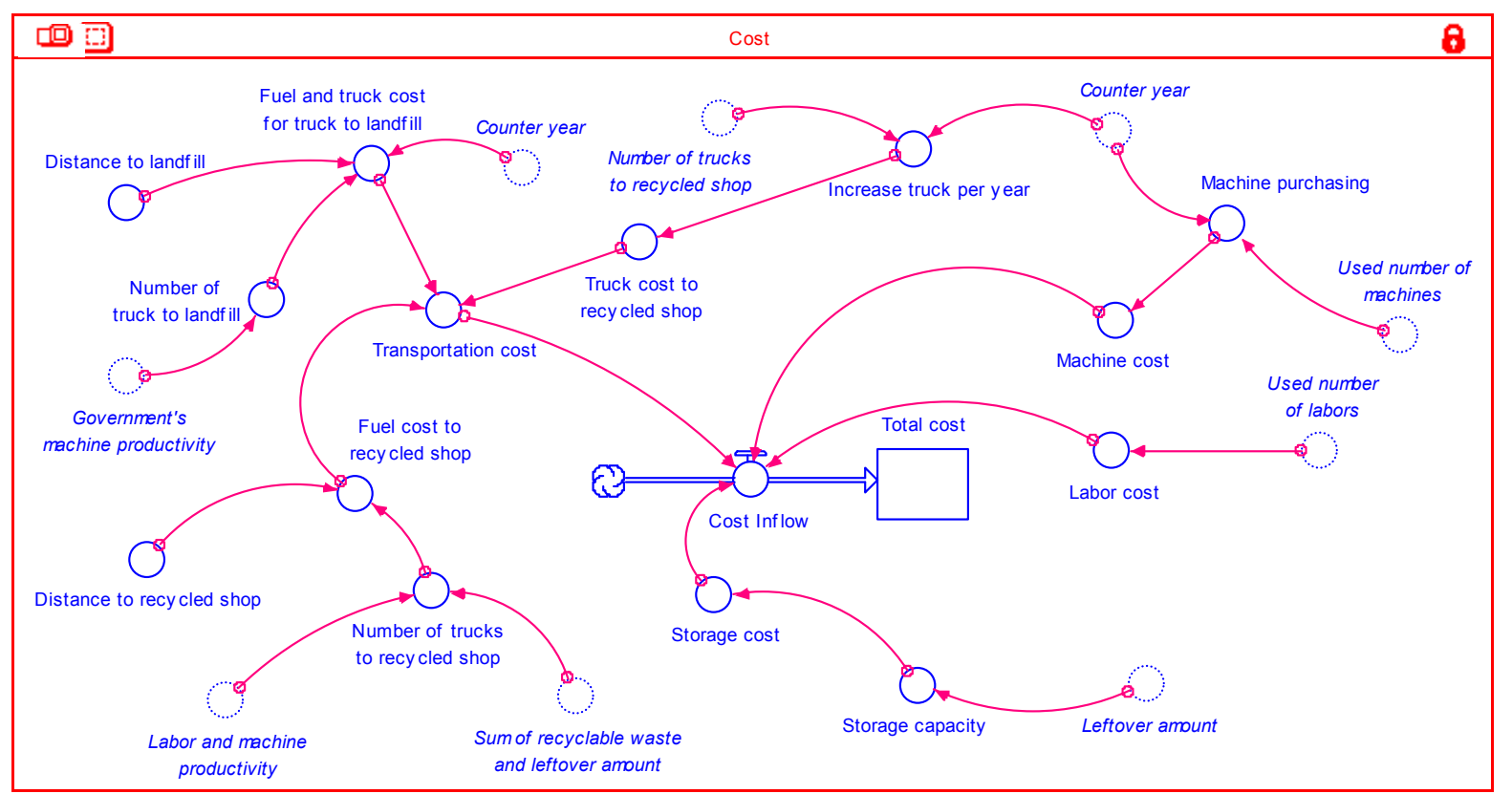

Fig. 1. The cost model.

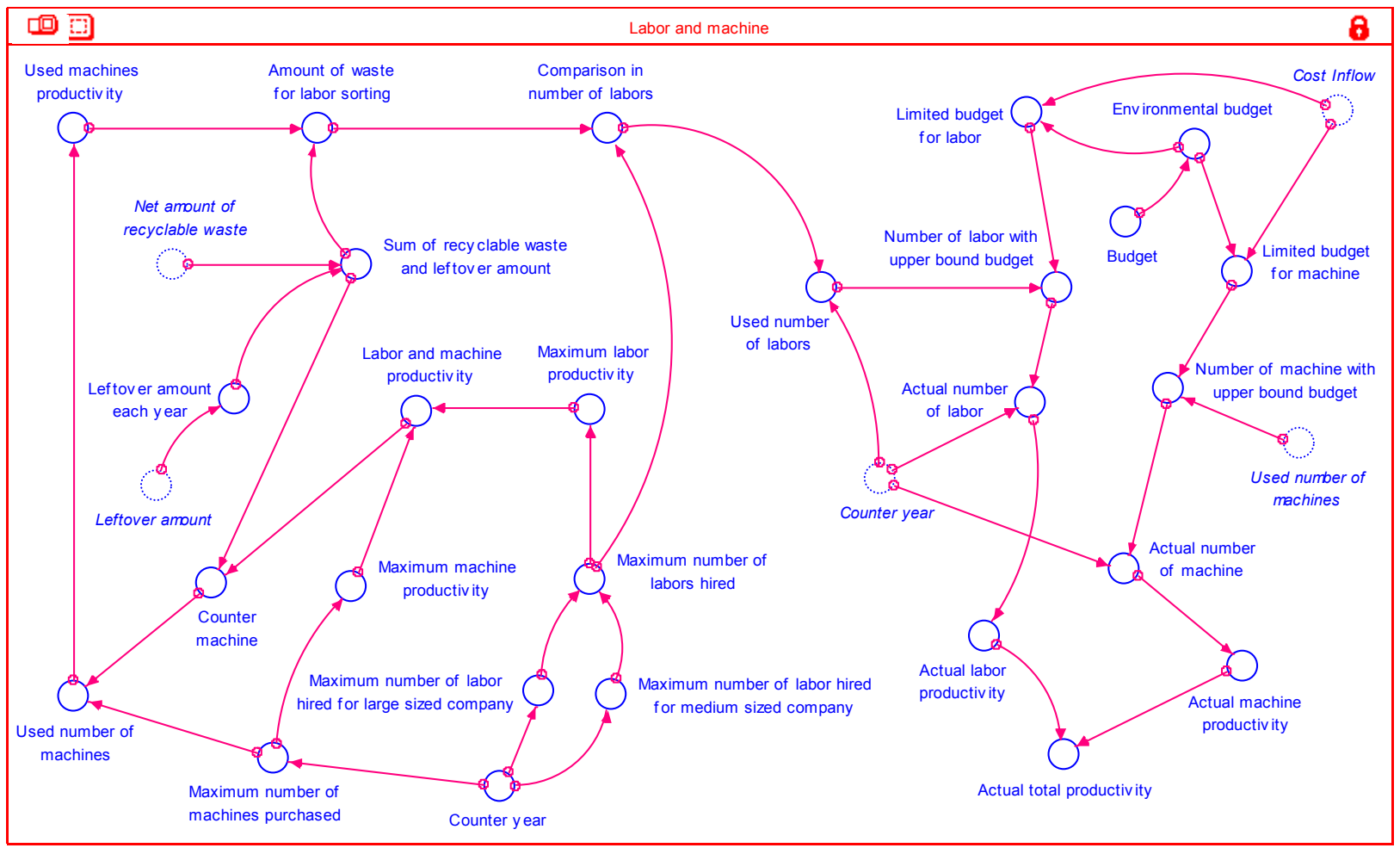

Fig. 2. The labor and machine productivity model.

Number of labor = MAX(history(Number_of_labor_ with_upper_bound_budget,Counter_year), $\overline{\text { HISTTORY }}$ (Number_of_labor_with_upper_bound_budget, Counter_year-1))

Number of machine $=$ MAX (history $($ Number of machine_with_upper_bound_budget,Counter_year), HISTORY(Number_of_machine_with_upper_bound budget,Counter_year-1),HISTORY(Number_of_ machine_with_upper_bound_budget,Counter_year-2))

Actual labor productivity $=$ Actual_number_of_labor* $(0.026 * 250)$
(5) Actual total productivity $=$ Actual_labor_productivity + Actual_machine_productivity

Actual machine productivity $=$ Actual_number_of machine $*(0.508 \times 8 \times 250)$

\section{The Leftover Sector}

In the early stage of recycling program, the amount of labor and machine are insufficient to sort the total recyclable waste. This, as a result, increases the leftover recycle amount at the end of each year. These leftovers are managed when there are available labors and machines. Fig. 3 shows the 
Leftover model. The leftover amounts at the end of each year are calculated from the total amount of C\&D wastes and the labor and machine productivity, see (10). The difference between the amount of wastes and the labor and machine productivities is the leftover of year 1 , see (11). If the leftover amount in year 1, together with the amount of wastes generated in year 2 , can be managed by labors and machines in year 2, then the leftover in year 2 is zero. This is vice versa if the labor and machine productivity is less than the amount of wastes to be sorted, as in (12).
Labor and machine productivity = Maximum_labor productivity+Maximum_machine_productivity

Leftover year 1 = IF(Count_year=1)THEN(Net_amount of_recyclable_waste-(Labor_and_machine_productivity)) ELSE (0)

Leftover year $2=\mathrm{IF}($ Count_year=2)THEN IF(Net_ amount_of_recyclable_waste+Leftover_year $1<$ Labor_ and_machine_productivity)THEN(0)ELSE(Net_amount of_recyclable_waste+Leftover_year1-Labor_and machine_productivity) $\operatorname{ELSE}(0)$

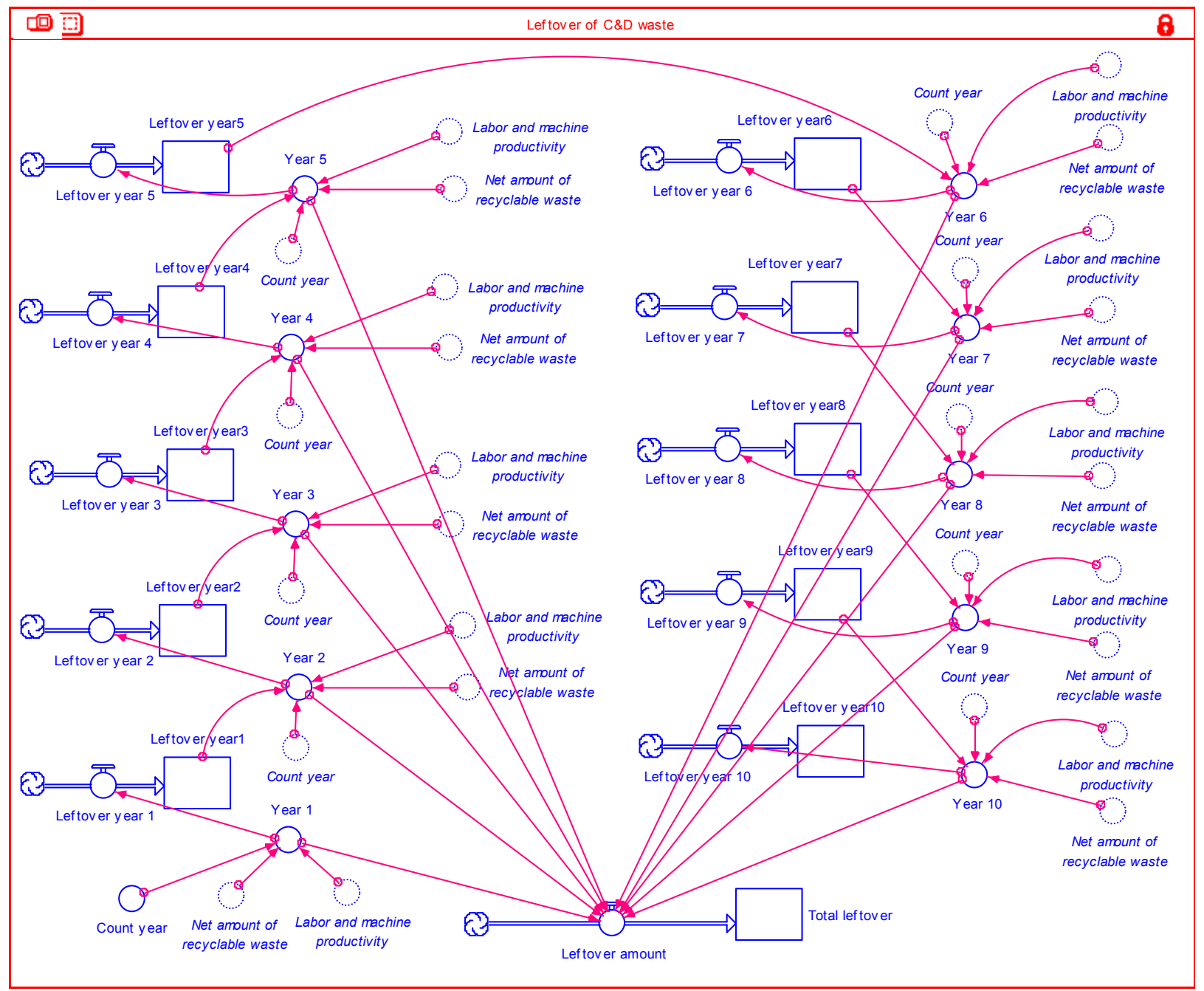

Fig. 3. The Leftover model.

\section{The Recycled Waste Sector}

Fig. 4 illustrates the relationships between the recycled waste and landfill. The "company's recycled amount" or CRA is a function of the "actual total productivity", the "leftover amount each year", the "government's machine productivity", and the "total recyclable amount", see (13)-(16). The amount of wastes recycled depends mainly on the company's total productivity. Once all the C\&D wastes are recycled, the total productivity remains constant, and the recyclable wastes to landfill becomes zero, as in (17). $\mathrm{CRA}=\mathrm{IF}(($ Total_recyclable_amount-Government's machine productivity+Leftover amount each year) $<$ Actual_total_productivity)THEN((Total_recyclable
amount-Government's_machine_productivity+Leftover amount each year)ELSE(Actual total productivity)

Actual total productivity $=$ Actual_labor_productivity + Actual_machine_productivity

Leftover amount each year $=$ DELAY $($ Leftover amount, 1,0)

Total recyclable amount $=$ Amount_of_waste generation $\times 0.7$

Amount of recyclable waste to landfill $=($ Total recyclable_amount -Government's_machine_productivity -Company's_recycled_amount_inflow)+Leftover_ 
amount_each_year

(17)

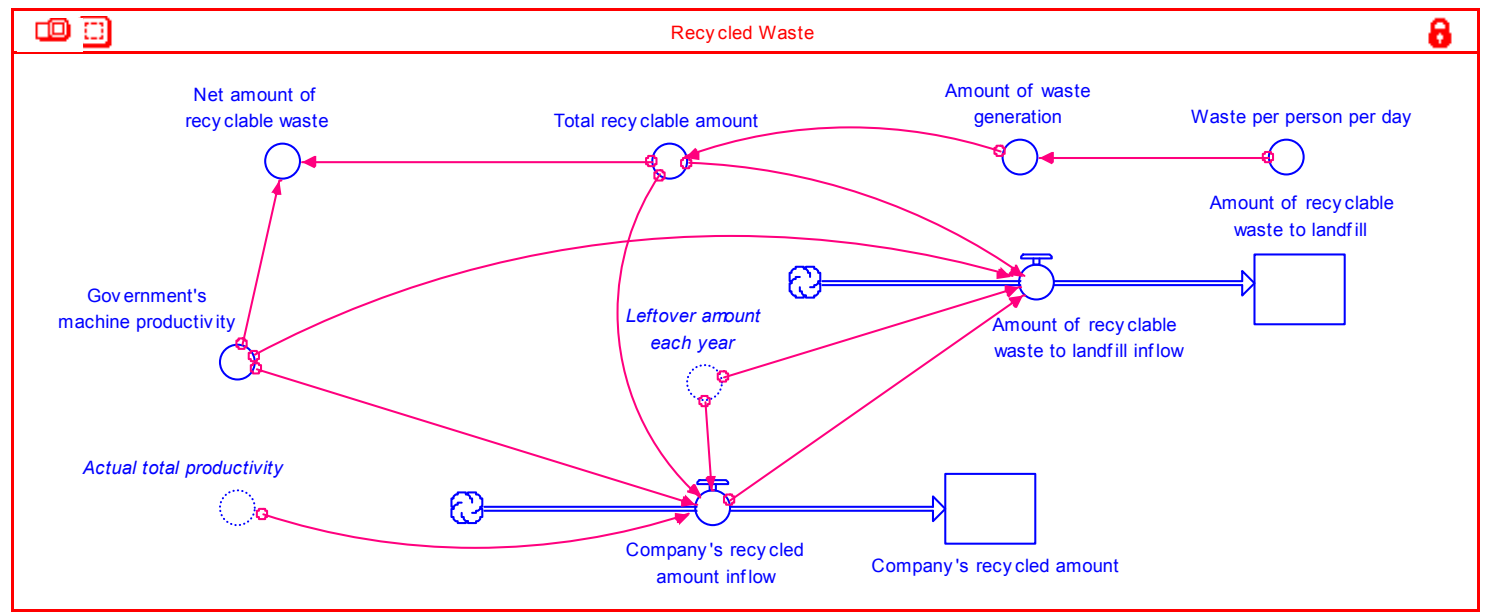

Fig. 4. The Recycled Waste model.

\section{The DynAmics Simulation Results}

The dynamic model of C\&D waste is simulated with the STELLA program. The simulation results, as illustrated in Fig. 5 and Table I, show that the amount of recycled waste increases as time increases. This is due to the increases of labors and machines.

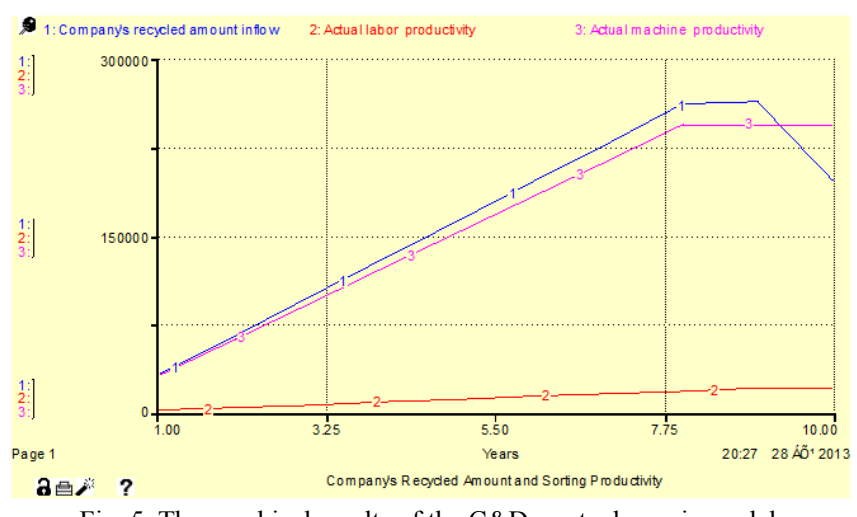

Fig. 5. The graphical results of the C\&D waste dynamic model.

TABLE I: ThE DyNAMIC SimULATION RESUlTS

\begin{tabular}{cccccc}
\hline Year & $\begin{array}{c}\text { Company's } \\
\text { Recycled Amount } \\
\text { (tons) }\end{array}$ & $\begin{array}{c}\text { Actual Labor } \\
\text { Productivity } \\
\text { (tons) }\end{array}$ & $\begin{array}{c}\text { Actual Machine } \\
\text { Productivity } \\
\text { (tons) }\end{array}$ & $\begin{array}{c}\text { Actual Number of } \\
\text { Labor } \\
\text { (persons) }\end{array}$ & $\begin{array}{c}\text { Actual Number of } \\
\text { Machine } \\
\text { (units) }\end{array}$ \\
\hline 1 & 32,040 & 1,560 & 30,480 & 240 & 30 \\
2 & 64,470 & 3,510 & 60,960 & 540 & 60 \\
3 & 97,290 & 5,850 & 91,440 & 900 & 90 \\
4 & 130,110 & 8,190 & 121,920 & 1,260 & 120 \\
5 & 162,930 & 10,530 & 152,400 & 1,620 & 150 \\
6 & 195,750 & 12,870 & 182,880 & 1,980 & 180 \\
7 & 228,570 & 15,210 & 213,360 & 2,340 & 210 \\
8 & 261,390 & 17,550 & 243,840 & 2,700 & 240 \\
9 & 263,730 & 19,890 & 243,840 & 3,060 & 240 \\
10 & $197,103.5$ & 19,890 & 243,840 & 3,060 & 240 \\
\hline
\end{tabular}

The company is capable of sorting all the recyclable waste (amount of waste initiated in a year plus the leftover) in nine years. This requires 3,060 labors and 240 machines (see Table I). The amount of recycled waste sorted in year 10 then drops to $197,103.50$ tons to cover only the amount of waste initiated in that year (with the leftover amount of zero).

It is investigated that the labor and machine productivities are constant after year 9, without further hiring and purchasing, respectively. The total cost after year nine is, therefore, kept constant (see Table II). From year 10 onwards, some labors are, consequently, transferred from the sorting and recycling activities to other related activities (due to decrease total waste to be sorted).

TABLE II: THE LABOR, MACHINE, AND TOTAL COSTS

\begin{tabular}{cccccc}
\hline Year & $\begin{array}{c}\text { Total Cost } \\
\text { (Baht) }\end{array}$ & $\begin{array}{c}\text { Labor Cost } \\
\text { (Baht) }\end{array}$ & $\begin{array}{c}\text { Machine Cost } \\
\text { (Baht) }\end{array}$ & $\begin{array}{c}\text { Transportation Cost } \\
\text { (Baht) }\end{array}$ & $\begin{array}{c}\text { Storage Cost } \\
\text { (Baht) }\end{array}$ \\
\hline 1 & $83,302,981.52$ & $18,000,000$ & $30,755,250$ & $34,547,731.52$ & 0 \\
2 & $78,580,114.47$ & $40,500,000$ & $30,755,250$ & $2,348,476,97$ & $4,976,387.5$ \\
3 & $109,299,834.92$ & $67,500,000$ & $30,755,250$ & $2,349,222.42$ & $8,695,362.5$ \\
4 & $138,742,642.88$ & $94,500,000$ & $30,755,250$ & $2,349,967.88$ & $11,137,425$ \\
5 & $166,908,538.33$ & $121,500,000$ & $30,755,250$ & $2,350,713,33$ & $12,302,575$ \\
6 & $193,797,521.29$ & $148,500,000$ & $30,755,250$ & $2,351,458.79$ & $12,190,812.5$ \\
7 & $219,409,591.74$ & $175,500,000$ & $30,755,250$ & $2,352,204.24$ & $10,802,137.5$ \\
8 & $243,744,749.7$ & $202,500,000$ & $30,755,250$ & $2,352,949.7$ & $8,136,550$ \\
9 & $233,746,999.7$ & $229,500,000$ & 0 & $52,949.7$ & $4,194,050$ \\
10 & $229,551,458.79$ & $229,500,000$ & 0 & $51,458.79$ & 0 \\
\hline
\end{tabular}

\section{CONCLUSION}

The dynamic model of C\&D waste is developed using the system dynamics modeling technique. The simulation results reveal the increase amount of recycled wastes over time, implying the decrease amount of waste to landfills. It must, however, be noted that the successful of C\&D waste recycling program comes from the cooperation between the government and the construction industry.

There are limitations in this study. Factors used in the dynamic model, such as are the inflation and the employment rates; derive from data in Bangkok, Thailand. Different data may affect to simulation results. The developed model, however, can be adapted in different environments by adjusting data accordingly to the specific situations.

\section{ACKNOWLEDGMENT}

The authors would like to thank the Office of Research Administration, Thammasat University, for the support of this study.

\section{REFERENCES}

[1] Pollution Control Department of Thailand. (December 2010). Solid waste generation in Thailand. [Online]. Available: http://www.pcd.go.th/info_serv/waste_wastethai48_53.html.

[2] K. Sorpimai, "Estimation of construction and demolition waste: Case of Bangkok metropolitan region," M.Sc. thesis, Asian Institute of Technology, Thailand, 2008.

[3] J. L. Hao and D. Scott, "A simulation model for construction joint venture projects in China," Journal of Construction Research, vol. 2, no. 1, pp. 103-107, 2001.

[4] J. L. Hao, V. W. Y. Tam, H. P. Yuan, J. Y. Wang, and J. R. Li, "Dynamic modeling of construction and demolition waste management processes: An empirical study in Shenzhen, China," Engineering 
Construction and Architectural Management, vol. 17, no. 5, pp. 476-492, 2010

[5] N. Lawson, I. Douglas, S. Garvin, C. McGrath, D. Manning, and J. Vetterlein, "Recycling construction and demolition wastes - A UK perspective," Environmental Management and Health, vol. 12, no. 2, pp. 146-157, 2001.

[6] Bureau of the Budget. (March 2011). Thailand's budget in brief fiscal year 2011. [Online]. Available: http://www.bb.go.th/FILEROOM/CABBBIWEBFORMENG/DRAW ER14/GENERAL/DATA0000/00000025.PDF.

[7] Strategy and Evaluation Department. (March 2012). Bangkok 12 year development plan phase 2 (B.E. 2556-2559). [Online]. Available: http://office.bangkok.go.th/pipd/02 Plan\%20BMA/01 Plan\%20Deve lopment $\% 20 \mathrm{BMA} /$ plan\%20development $\% 2012 \% 20$ year\%20time $\% 20$ $2 \% 20(\% 202556-2559)$.pdf.

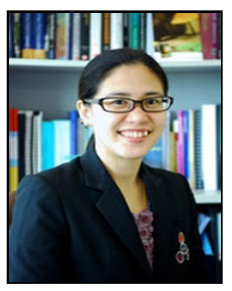

Thanwadee Chinda was born in Ratchaburi, Thailand on $31^{\text {st }}$ March 1978. She has received her Ph.D. in engineering management from Griffith University, Gold Coast, Australia in 2008 .

She has currently worked as a lecturer at Sirindhorn International Institute of Technology, Thammasat University, Pathumthani, Thailand. She has published a number of journal papers in the International Journal of Occupational Safety and Ergonomics, Engineering Management Journal, and Songklanakarin International Journal of Science and Technology.

Asst. Prof. Dr. Thanwadee Chinda is currently a member of Engineers Australia and the Engineering Institute of Thailand. 